\title{
Exploring Epidemiological Behavior of Novel Coronavirus (COVID-19) Outbreak in Bangladesh
}

\author{
Samrat Kumar Dey ${ }^{1}$ (D) $\cdot$ Md. Mahbubur Rahman ${ }^{2} \cdot$ Umme Raihan Siddiqi $^{3} \cdot$ Arpita Howlader $^{4}$
}

Accepted: 20 August 2020 / Published online: 26 August 2020

(C) Springer Nature Switzerland AG 2020, corrected publication 2020

\begin{abstract}
Globally, there is an obvious concern about the fact that the evolving 2019-nCoV coronavirus is a worldwide public health threat. The appearance of severe acute respiratory syndrome coronavirus 2 (SARS-CoV-2) in China at the end of 2019 triggered a major global epidemic, which is now a major community health issue. As of August 13, 2020, according to the Institute of Epidemiology, Disease Control and Research (IEDCR), Bangladesh has reported 269,095 confirmed cases between 8 March and 13 August 2020, with $>1.30 \%$ of mortality rate and $>57 \%$ of recovery rate. COVID-19 outbreak is evolving so rapidly in Bangladesh; therefore, the availability of epidemiological data and its sensible analysis are essential to direct strategies for situational awareness and intervention. This article presents an exploratory data analysis approach to collect and analyze COVID-19 data on epidemiological outbreaks based on the first publicly available COVID-19 Daily Dataset of Bangladesh. Various publicly open data sources on the outbreak of COVID-19 provided by the IEDCR, World Health Organization (WHO), Directorate General of Health Services (DGHS), and Ministry of Health and Family Welfare (MHFW) of Bangladesh have been used in this research. Visual exploratory data analysis (V-EDA) techniques have been followed in this research to understand the epidemiological characteristics of COVID-19 outbreak in different districts of Bangladesh between 8 March 2020 and 13 August 2020 and these findings were compared with those of other countries. In all, this is extremely important to promptly spread information to understand the risks of this pandemic and begin containment activities in the country.
\end{abstract}

Keywords COVID-19 BD Dataset · Outbreak $\cdot$ Data analysis $\cdot$ Coronavirus $\cdot$ Visualization $\cdot$ SARS-CoV-2 $\cdot$ Bangladesh

Samrat Kumar Dey

sopnil.samrat@gmail.com

Md. Mahbubur Rahman

mahbub.rahman.cse@gmail.com

Umme Raihan Siddiqi

u.raihan.siddiqi@gmail.com

Arpita Howlader

arpita.cce.pstu@gmail.com

1 Department of Computer Science and Engineering (CSE), Dhaka International University (DIU), Dhaka 1205, Bangladesh

2 Department of Computer Science and Engineering (CSE), Military Institute of Science and Technology (MIST), Mirpur Cantonment, Dhaka 1216, Bangladesh

3 Department of Physiology, Shaheed Suhrawardy Medical College (ShSMC), Dhaka 1207, Bangladesh

4 Department of Computer and Communication Engineering (CCE), Patuakhali Science and Technology University (PSTU),

Dumki, Patuakhali 8602, Bangladesh

\section{Background}

Bangladesh is a democratic nation surrounded by east, west, and north India, Myanmar from southeast with Bay of Bengal on the southern side. As of 1 July 2017, the population size in Bangladesh is estimated at 162.7 million (male female ratio is 100.2:100). It has a unitary form of government, without a province or a territory. There are 64 districts in the country and again each district is divided into several sub districts (which is called upazilas). Right now, there are eight divisions (Barisal, Chittagong, Dhaka, Khulna, Mymensingh, Rajshahi, Rangpur, and Sylhet) in the country and each division is named after the major city within its jurisdiction, which also acts as the administrative headquarter of that division. The Ministry of Health and Family Welfare (MoHFW) is responsible for the preparation and management of curative, preventive, and pro-active health services for the population of the country and therefore considered one of the largest ministries of the Government of Bangladesh. The Institute of Epidemiology, Disease Control and Research (IEDCR) is 
Table 1 Tabular representation of Bangladesh COVID-19 Daily Dataset with column description

Bangladesh COVID-19 Daily Dataset

\begin{tabular}{|c|c|c|}
\hline Data files & Columns & Description \\
\hline \multirow[t]{10}{*}{ COVID-19 BD Dataset-13 August.csv } & Date & Specific date \\
\hline & Daily new confirmed cases & Day-wise new confirmed case reported \\
\hline & Total confirmed cases & Aggregate confirmed cases of each day \\
\hline & Daily new deaths & Day-wise new death case reported \\
\hline & Total deaths & Aggregate death cases of each day \\
\hline & Daily new recovered & Day-wise new recovered case reported \\
\hline & Total recovered & Aggregate recovered cases of each day \\
\hline & Daily new tests & Day-wise number of new test performed \\
\hline & Total tests & Cumulative number of test of each day \\
\hline & Active cases & Until date number of active patient \\
\hline \multirow[t]{4}{*}{ COVID-19 BD Isolation statistics.csv } & Date & Specific date \\
\hline & Total isolation & Cumulative isolated patients until date \\
\hline & Currently in isolation & Number of isolation patients until now \\
\hline & Release from isolation & Number of patients released from isolation \\
\hline \multirow[t]{4}{*}{ COVID-19 BD Quarantine statistics.csv } & Date & Specific date \\
\hline & Total quarantine & Cumulative quarantine persons until date \\
\hline & Currently in quarantine & Number of quarantine persons until now \\
\hline & Release from quarantine & Number of person released from quarantine \\
\hline \multirow[t]{3}{*}{ COVID 19 BD District wise confirmed cases.csv } & Division & Name of the division \\
\hline & District & Name of the district \\
\hline & Number of confirmed cases until date & Cumulative case number \\
\hline \multirow{2}{*}{$\begin{array}{l}\text { COVID } 19 \text { BD Dhaka location wise } \\
\text { confirmed cases.csv }\end{array}$} & City/location & Dhaka city location \\
\hline & Number of confirmed cases until date & $\begin{array}{l}\text { Aggregate confirmed cases of each day } \\
\text { until date at Dhaka City }\end{array}$ \\
\hline
\end{tabular}

considered the focal institute for conducting public health surveillance and outbreak response. During the last few years, however, the efficiency of the International Health Regulation (IHR) has dramatically increased and exceeded $68 \%$ in the country [1]. Moreover, it also has the national ability to test COVID-19 patients by using polymerase chain reaction (PCR) machine confirmed laboratory. The first case of pneumonia of unknown origin identified in Wuhan City, the capital of Hubei Province, China in early December 2019 was later determined as a non-SARS novel coronavirus by the Chinese Center for Disease Control and Prevention (CDC) [2]. Coronaviruses are non-segmented positive-sense RNA viruses that belong to the Coronaviridae family and the Nidovirales order and are widely distributed in humans and other mammals [3]. The pathogen has been described as a novel enveloped RNA betacoronavirus [4] commonly referred to as severe acute respiratory coronavirus 2 syndrome (SARS-CoV-2), having a phylogenetic resemblance to SARS-CoV [5]. With a mortality rate of $10 \%$ for SARS$\mathrm{CoV}$ and $37 \%$ for MERS-CoV [6, 7], the epidemics of the two beta coronaviruses, severe acute respiratory syndrome coronavirus (SARS-CoV) [8, 9], and Middle East respiratory syndrome coronavirus (MERS-CoV) [10, 11], have caused more than ten thousand cumulative cases in the last two decades. With no surprise, on 30 January 2020, the World Health Organization (WHO) declared the COVID-19 outbreak as a Public Health Emergency of International Concern (PHEIC) [12]. As of August 13, 2020, a total of 20,439,814 laboratory-confirmed cases have been documented globally and among them, Bangladesh has confirmed 269,095 cases with a death rate of $1.32 \%$ [13]. This report will investigate Bangladesh's epidemiological data based on the country's first COVID-19 Daily Dataset between March 8, 2020 and August 13, 2020. Between 8 March and 10 August 2020, according to the IEDCR, there were 260,507 COVID-19 confirmed by rt-PCR, including 3438 reported death cases. Based on the previous reported week (until 3 August 2020), in comparison with the previous epidemiological week, the number of new weekly COVID-19 cases decreased by $2.5 \%$ (16,854 and 17,293 respectively) while the number of COVID-19 new weekly deaths increased by $8.4 \%$. On February 5, 2020, the IEDCR performed coronavirus tests on 39 Bangladeshis for the very first time, those who came back to Bangladesh from China on that time. Until then, none 


\section{a}

Date wise confirmed cases of COVID-19

(Bangladesh case analysis till August 13, 2020)

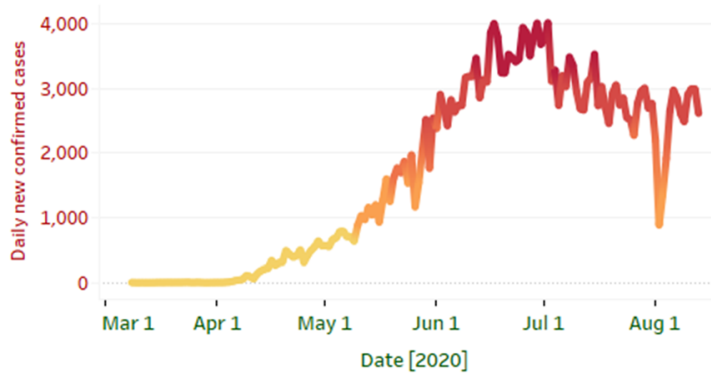

C

Date wise recovered cases of COVID-19

(Bangladesh case analysis till August 13, 2020)

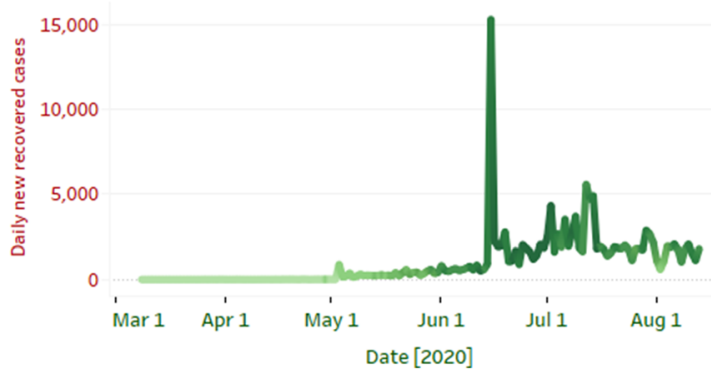

Fig. 1 Graphs provide an overview of how COVID-19 is spreading in Bangladesh for the last 156 days (from 8 March 2020 to 13 August 2020). Until date, Bangladesh has confirmed 269,095 laboratory tested COVID19 positive patients. a The specific date-wise number of confirmed cases for each day. b The number of death case reported each day. Until 13

of them found infected with the virus. In these circumstances, turning public fears into reality, on 8 March 2020, Bangladesh has confirmed its first case of COVID-19 patients $(N=3)$ caused by SARS-CoV-2 virus. Among these, two of the three infected were all aged between 20 and 35 and returned recently to Bangladesh from different cities in Italy. However, this is significant that, only after 7 days of the first confirmed COVID-19 reported case, on 16 March 2020, the IEDCR reported that the virus had begun to spread locally, and indicated that children in the country had been infected with coronavirus for the very first time. As the outbreak of COVID19 is expanding rapidly globally, already appeared as a global pandemic, therefore we aim to describe the number of different cases caused by SARS-CoV-2 and represent the epidemiological data through visual exploratory data analysis (EDA) [14] approach. Considering COVID-19's rapid spread, we have designed a comprehensive daily dataset [15] and decided that an updated case review with outbreak analysis in Bangladesh may help identify the epidemiological characteristics and severity of the disease across the country. Apart from preparing an inclusive dataset, this research will also analyze the different trend of documented cases of COVID19 in the countries of the South East Asian Region (SEAR), and South Asian Association for Regional Cooperation

\section{b}

Date wise death cases of COVID-19

(Bangladesh case analysis till August 13, 2020)

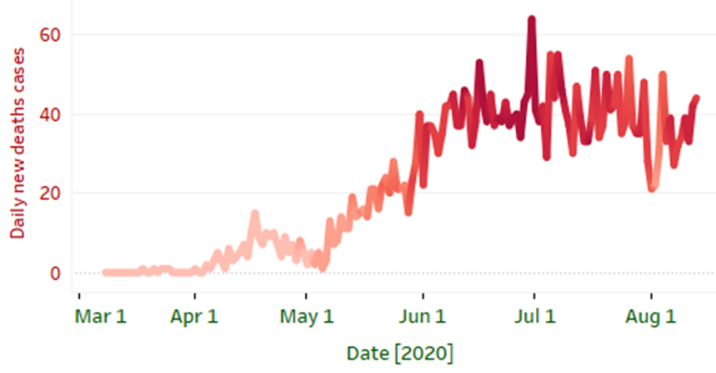

d

Date wise active cases of COVID-19

(Bangladesh case analysis till August 13, 2020 )

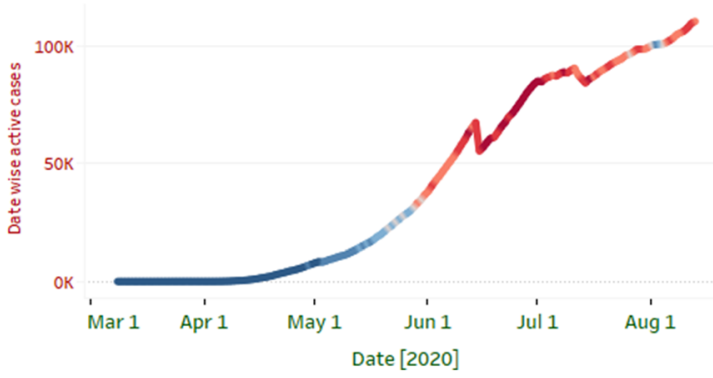

August 2020, Bangladesh has reported 3557 (1.32\%) deaths from 18 March 2020 (first death case reported). c and d The date-wise number of recovered patients $154,871(57.55 \%)$ from COVID-19 and available patients under treatment $41.12 \%(110,667)$ until 13 August 2020

(SAARC). Moreover, this work would pose a concern for the citizens of Bangladesh, whether the situation of COVID19 in the country is on the verge of a rapid outbreak in the near future or if it can flatten the curve. As of August 15, 2020, according to the situation report provided by the IEDCR [16], thirty-four (34) new death cases taking the total number of death cases to 3625 in the country and confirmed case raised to 274,525 .

\section{Methods}

In this research, we have used numerous range of data sources for preparing our datasets. This dataset is named as "Bangladesh COVID-19 Daily Dataset" available at this URL: https://www.kaggle.com/samratkumardey/bangladeshcovid19-daily-dataset. As per our knowledge, "Bangladesh COVID-19 Daily Dataset" is the first designed and developed dataset that enlist the different cases (confirmed, death, recovered, number of test, etc.) of COVID-19 outbreak in Bangladesh. We use official government sources which include (a) daily press briefing provided by IEDCR, (b) press releases from official website of Corona BD (https://corona. gov.bd/), (c) press releases on the official websites of 
Ministries of Health (http://www.mohfw.gov.bd/), and Directorate General of Health Services (DGHS) (https:// dghs.gov.bd/index.php/en/). In order to prepare a comprehensive and precise dataset, we collected data on the following: (i) daily dates, which include the date of daily new confirmed case, total confirmed case, daily new deaths, total deaths, daily new recovered, total recovered, daily new tests, total tests, and active cases; (ii) geographic information, division and district-wise confirmed cases; (iii) demographic statistics about the patient's age and sex; and (iv) date-wise statistics of quarantine and isolated patients. Table 1 provides insight on Bangladesh COVID-19 Daily Dataset and their respective data files with their column description. As this is a time series data, therefore the number of instances on a given day is the cumulative number. This dataset contains different COVID-19 case data from 8 March 2020 to 13 August 2020. It is to be notated that Bangladesh has familiarized with its very first laboratory tested confirmed COVID-19 patients on 8 March 2020 and it reported its first death case on 18 March 2020. Our research team believes that these data should be available to policy makers, health professionals, and data analysts and should be readily accessible.

\section{Results}

This exploratory data analysis (EDA) mainly focused on the COVID-19 outbreak of a South East Asian country, Bangladesh. Apart from designing and developing a dataset, this research also analyzed the different characteristics of COVID-19 epidemic between 8 March 2020 and 13 August 2020. All the data analysis and comparative results are based on the data that we collected and curated individual-level data from the national level, division level, district level, and official health reports provided by government officials, as well as additional information from the WHO situation report. As of 15 August 2020, according to the Institute of Epidemiology, Disease Control and Research (IEDCR), there are 274,525 confirmed COVID-19 cases by rt-PCR in Bangladesh, including 157,635 patients who have recovered and 3625 related deaths; case fatality rate (CFR) is $1.32 \%$. Figure 1 shows the daily distribution of confirmed, deaths, recovered, and active COVID-19 cases from 08 March 2020 to 13 August 2020 in Bangladesh. Between 1 March 2020 and 10 August 2020, out of the total 260,507 COVID-19 cases, $57.75 \%$ (150437) were cured, $1.32 \%$ (3438) died, and $40.93 \%$ (106632) were active cases with $72 \%(187,565)$ males and $28 \%(72,941)$ females reported confirmed cases respectively. Until 10 August, Bangladesh has reached to its epidemiological week of 22 since its first confirmed case of COVID-19. In epidemiological week 22, the number of COVID-19 active cases increased by $3.7 \%$, in comparison with the previous week (week 21) $(102,954$ and 99,243 ) and at the same time, the number of recovered COVID-19 cases decreased by $11.0 \%$ (11,531 and 12,240 respectively). Distribution of confirmed and deaths of COVID-19 cases by age, gender, and division is shown on Table 2. As of 10 August 2020, 26.9\% cases were confirmed

Table 2 Distribution of COVID-19 confirmed and death cases by Age, gender, and division, 08 March-10 August 2020 in Bangladesh

$\begin{array}{lll}\text { Age distribution of death patients } & \\ \text { Age group } & \text { Number of death cases } & \text { Percentage } \% \\ >60 \text { years } & 1622 & 47.18 \% \\ 51-60 \text { years } & 981 & 28.53 \% \\ 41-50 \text { years } & 474 & 13.79 \% \\ 31-40 \text { years } & 219 & 6.37 \% \\ 21-30 \text { years } & 90 & 2.62 \% \\ 11-20 \text { years } & 33 & 0.96 \% \\ 0-10 \text { years } & 19 & 0.55 \% \\ \text { Total } & (N=3438) & 100 \% \\ \text { Gender distribution of confirmed patients } & \\ \text { Sex } & \text { Number of confirmed cases } & \text { Percentage } \% \\ \text { Male } & 187,565 & 72 \% \\ \text { Female } & 72,941 & 28 \% \\ \text { Gender distribution of death patients } & \\ \text { Sex } & \text { Number of death cases } & \text { Percentage } \% \\ \text { Male } & 2716 & 79 \% \\ \text { Female } & 722 & 21 \%\end{array}$

Distribution of confirmed COVID-19 death cases by division

$\begin{array}{lll}\text { Division } & \text { Number of death cases } & \text { Percentage \% } \\ \text { Barisal } & 137 & 4 \% \\ \text { Chittagong } & 830 & 24 \% \\ \text { Dhaka } & 1586 & 46 \% \\ \text { Khulna } & 263 & 7 \% \\ \text { Mymensingh } & 76 & 2 \% \\ \text { Rajshahi } & 211 & 6 \% \\ \text { Rangpur } & 138 & 4 \% \\ \text { Sylhet } & 158 & 5 \% \\ \text { Unknown } & 39 & 1.13 \% \\ \text { Total } & (N=3438) & \sim 100 \%\end{array}$

Age-sex distribution of the reported confirmed COVID-19 deaths

\begin{tabular}{lll} 
Age group & Male & Female \\
$>80$ years & $5.2 \%$ & $1.5 \%$ \\
$71-80$ years & $15.9 \%$ & $3.0 \%$ \\
$61-70$ years & $24.4 \%$ & $6.3 \%$ \\
$51-60$ years & $19.8 \%$ & $4.4 \%$ \\
$41-50$ years & $8.2 \%$ & $2.1 \%$ \\
$31-40$ years & $4.0 \%$ & $1.7 \%$ \\
$21-30$ years & $1.1 \%$ & $1.0 \%$ \\
$11-20$ years & $0.5 \%$ & $0.4 \%$ \\
$0-10$ years & $0.1 \%$ & $0.3 \%$ \\
Total & $\sim 79 \%$ & $\sim 21 \%$ \\
\hline
\end{tabular}


in people between 31 and 40 years old, followed by $20.7 \%$ in the age group of 21 to $30,18.8 \%$ in the age group of $41-50$ years, and $15.0 \%$ in the age group between 51 and 60 years old. The highest death rate (30.7\%) was reported in the age group of 6170 years old, $25.6 \%$ in the older age group of 71 and above, and $24.2 \%$ in the age group between 51 and 60 years.

It is evident that there has been an increasing trend in the number of reported confirmed cases since 3 April 2020, due to expansion of COVID-19 testing in the country and establishing testing capacity in 85 laboratories until now (Fig. 2). By 10 August 2020, according to the IEDCR, 1,273,168 COVID-19 samples were tested with the overall positivity rate of $20.46 \%$ in Bangladesh with the support of 49 laboratories (57.6\%) in Dhaka City and 36 laboratories (42.4\%) outside Dhaka. However, COVID-19 testing coverage has been gradually increasing in Bangladesh, reaching 7485/1,000,000 population until 10 August 2020. Figure 1 shows the date-wise daily distribution of confirmed COVID-19 cases from 08 March to 13 August 2020 in Bangladesh. Dhaka remains the area of the highest concentration of the reported COVID-19 cases (Fig. 3). As of 10 August, $64.7 \%(168,548 / 260,507)$ of all confirmed cases were reported form Dhaka Division,

\section{a}

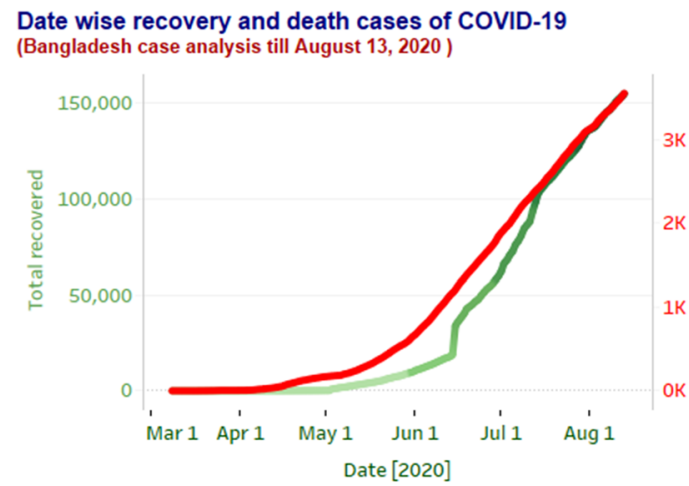

C

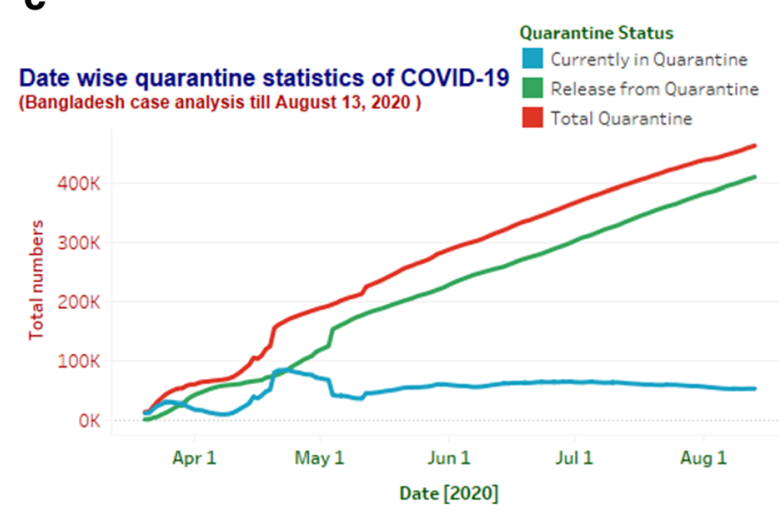

Fig. 2 This graphical analysis will lead us to understand the current situation of COVID-19 outbreak in Bangladesh. a A comparative datewise representation of death cases with recoveries. Until 13 August 2020, Bangladesh has reported $1.32 \%$ (3557) death cases, whereas $57.55 \%$ $(154,871)$ patients recovered successfully among 269,095 confirmed patients. b Another date-wise comparison of the number of COVID-19 tests followed by Chittagong Division 14.4\% (37,513/260,507), Rajshahi Division 5.5\% (14,327/260,507), Khulna Division $5.1 \%(13,285 / 260,507)$, Sylhet Division $3.2 \%$ (8336/260,507) Rangpur Division 2.7\% (7033/260,507), and Barisal Division $2.5 \%(6512 / 260,507)$ and the remaining $1.9 \%(4949 / 260507)$ were lowest reported from Mymensingh Division.

As of 13 August, there were 52,902 individuals at quarantine (both in home and institutional quarantine); since the day home quarantine was established in the country to 13 August 2020, a total of 462,062 individuals were quarantined and of them $88.55 \%$ (409161) were released (Fig. 2). Similarly, a total of 60,020 individuals were documented in isolation (until 13 August 2020), whereas a total of $32.83 \%(19,708)$ individuals were currently in isolation; among them, $67.12 \%$ $(40,312)$ were released from isolation until 13 August 2020. A date-wise recovery with death case analysis and number of test performed each day with the number of confirmed cases is also presented in this research (Fig. 2).

However, as of 10 August 2020, COVID-19 case doubling time varies in different divisions of the country. Case doubling time was 12.5 days in Dhaka Division, 15 days in Chittagong

\section{b}

Date wise test performed and confirmed cases of COVID-19

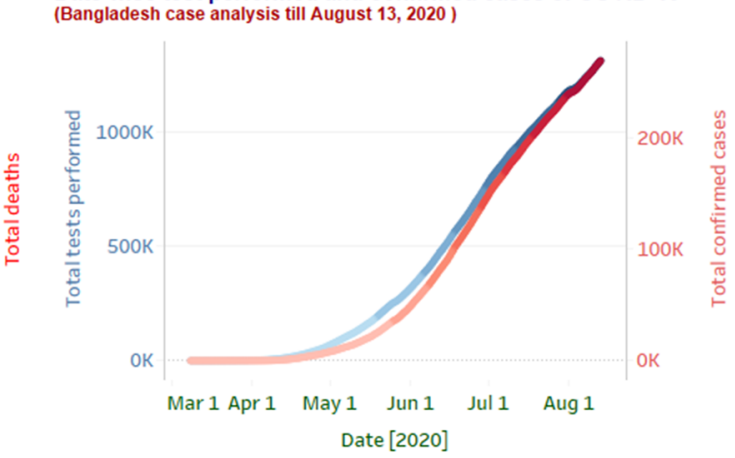

d

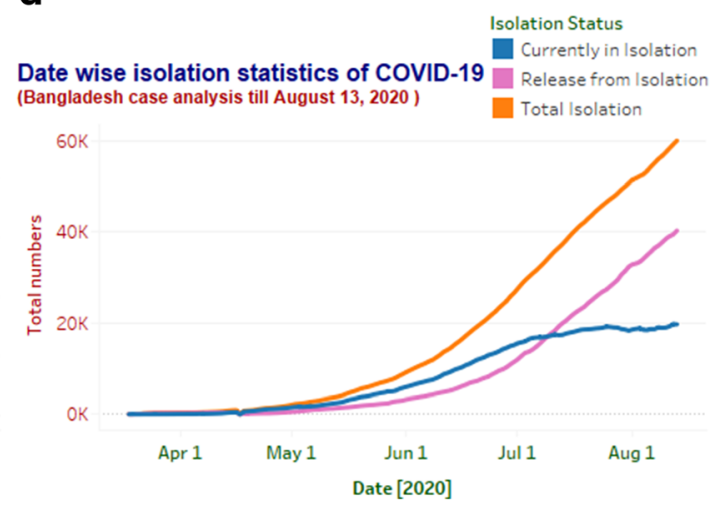

performed and the number of confirmed cases is shown. With time, the number of the test-performed curve rises along with the total reported confirmed case. Around 1,316,543 tests performed until 13 August 2020 and among them 269,095 patients found COVID-19 positive. c and $\mathbf{d}$ The date-wise quarantine and isolation statistics for the 159 days managed by the Government of Bangladesh 


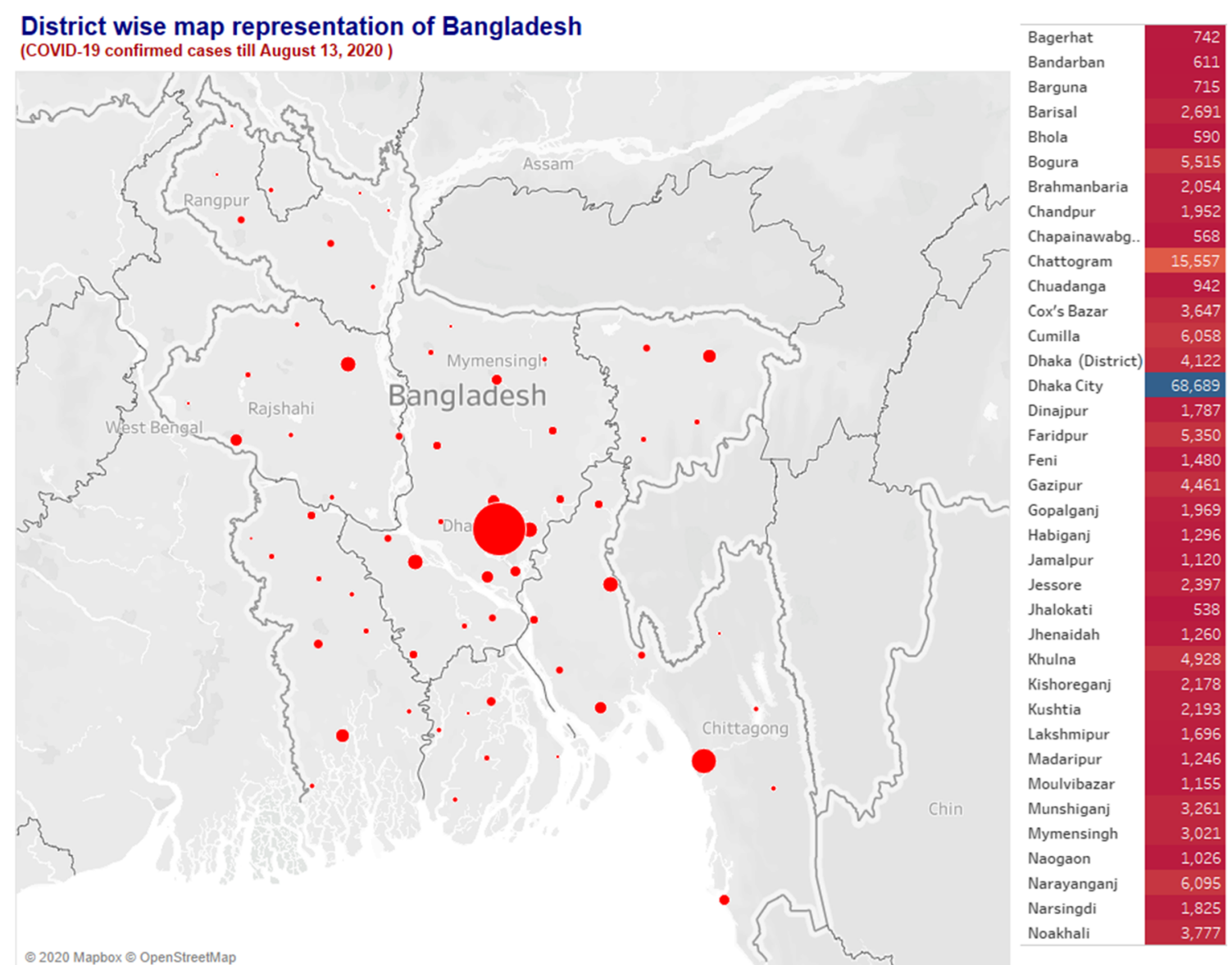

Fig. 3 Distribution of COVID-19 laboratory tested confirmed cases in different districts of Bangladesh from 8 March 2020 to 13 August 2020 . Dhaka, the capital of the country, shows the highest number of reported COVID-19 confirmed cases

and Khulna, fluctuates between 16 and 20 days in Rajshahi, Sylhet, and Barisal divisions, and more than 20 days in Mymensingh and Rangpur divisions.

Until 10 August 2020, Bangladesh overall attack rate (AR) of the country was 1529.6 per 1 million and $100 \%(64 / 64)$ of districts with the total population of 170,306,468 people have reported confirmed COVID-19 cases. Moreover, on epidemiological week 22 , weekly attack rate increased by $7.0 \%$ in comparison with the previous week (1513 and 1414 respectively). The highest attack rate continues to be observed in the Dhaka Division until 10 August 2020. Dhaka City reported the highest AR $(15,904.7 / 1,000,000)$ followed by Faridpur (2365), Narayanganj (1730.5), Munshiganj (1668.6), Gopalganj (1332.4), Rajbari (1286.7), Gazipur (1088.1), Shariatpur (916.9), Madaripur (897.3), Dhaka District (690.2), Narsingdi (685.4), Kishoreganj (624.5), and Manikganj (550.2) and the lowest AR 438.7 per 1 million was reported from Tangail District. However, the second, third, and fourth attack rates were reported from Chittagong $(1102.4 / 1,000,000)$, Khulna $(766.9 / 1,000,000)$, and Sylhet $(715.4 / 1,000,000)$ respectively. Barishal $(649.3 / 1,000,000)$,
Rangpur (400.9/1,000,000), and Mymensingh divisions (379.9/1,000,000) reported the comparatively lowest attack rate comparing with other divisions of the country.

Due to geographic orientation, Bangladesh is enlisted as a country of South East Asian Region (SEAR) and it also works together with the South Asian Association for Regional Cooperation (SAARC) forum. Therefore, this research also compares the confirmed and mortality ratio in terms of days with these neighboring countries of the same region. However, this study also covers countries that had higher mortality rates worldwide until August 13, 2020 (Fig. 4). This study correlates Bangladesh with SEAR, SARRC, and top 10 countries (based on the highest number of confirmed cases and recorded deaths) in terms of the number of days it takes to show a similar trend based on confirmed and mortality case pattern.

\section{Discussion}

We report here all the different cases of COVID-19 outbreak in Bangladesh based on daily dataset and compare its results 
a

Confirmed COVID-19 Deaths (SAARC, SEAR \& top 10 countries)

(Number of days since the 5 th total confirmed death till 13 August, 2020)

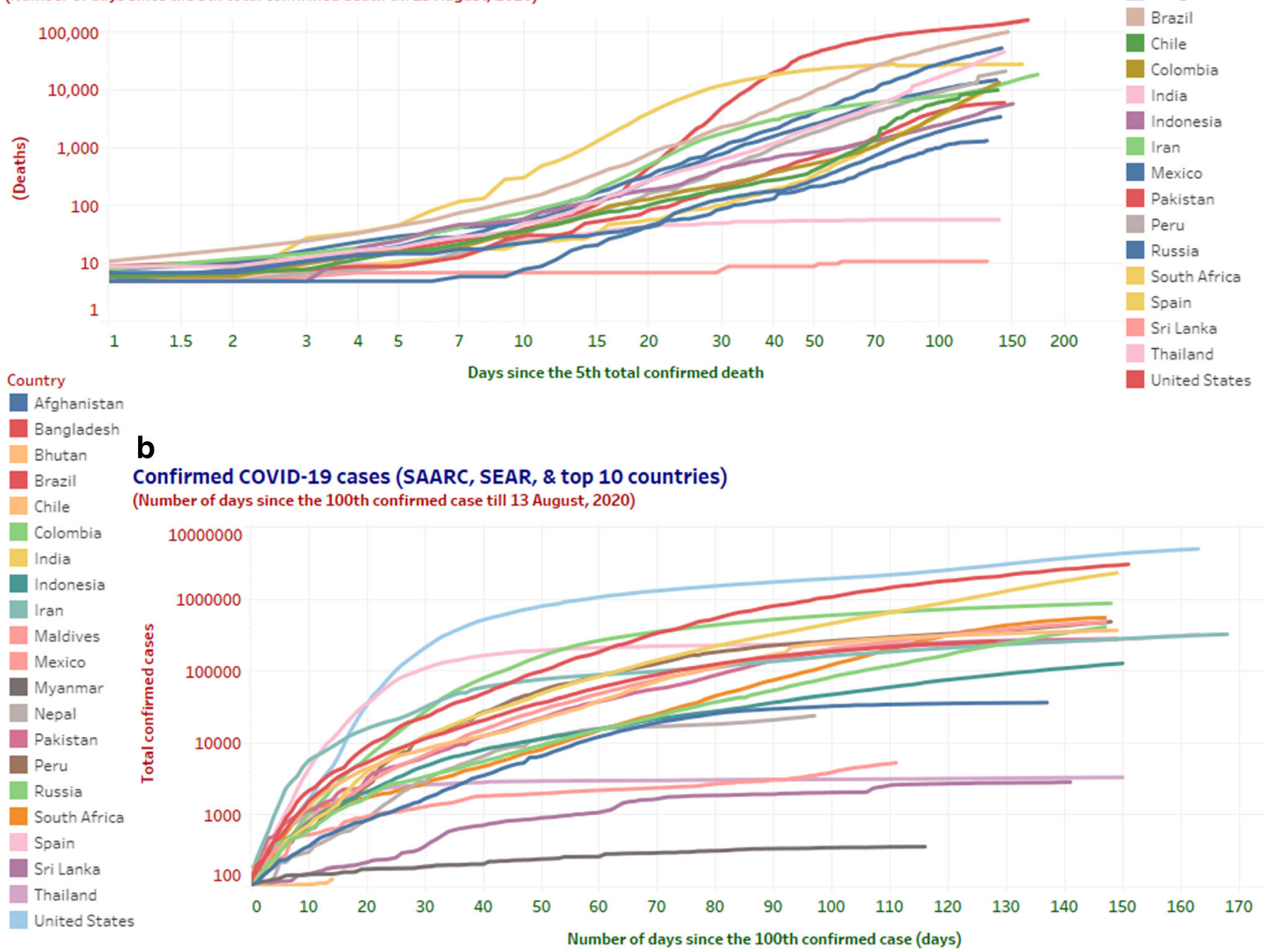

Fig. 4 Comparative analysis in terms of days since the fifth total confirmed death and number of days since the 100th confirmed cases with SAARC, SEAR, and top 10 countries (based on confirmed cases and highest death reported)

with the countries of South Asian Association for Regional Cooperation (SAARC), South East Asian Region (SEAR), and globally top ten countries in terms of their daily confirmed and death rate between 8 March 2020 and 13 August 2020. Moreover, design and development of country's first "Bangladesh COVID-19 Daily Dataset" are also focused in this research. Like other South Asian countries, Bangladesh also outlined measures and plans to face this severe pandemic of COVID-19 with utmost importance. When an outbreak such as this occurs, readily available data and knowledge are equally essential to continue the evaluation required to identify the threats and begin outbreak containment activities. From the observation, it is evident that for Bangladesh the number of total confirmed death has doubled in the last 46 days (1783 deaths on June 30 and 3591 deaths on August 15, 2020). On the other hand, the number of total confirmed cases has doubled in the last 48 days $(133,978$ cases on June 28 and 271,881 cases on August 15, 2020).
Overall case doubling time in Bangladesh has slowed to 13.5 days until 10 August 2020 (1.0 days more in comparison with epidemiological week 21). It is also notable that the number of confirmed cases in the country increased rapidly as the conduction of number of test increased in passage of time. As of 10 August, total COVID-19 test per 1000 people was 7.73. However, until 13 August 2020, 100\% (64/64) district of the country has already been infected with at least more than three hundred (>300) confirmed COVID-19 cases. Until now (14 August 2020), Bangladesh has only reported 9.278\% (269,115/2,900,347 cases) of confirmed cases in South East Asian Region with a case fatality rate of 6.15\% (3557/57,756 death cases). Importantly, regarding the trend analysis of daily-confirmed cases in terms of number of days since the 100th confirmed cases, Bangladesh (263,503 cases on the 127 days of 100 confirmed cases) shows the similar trend until now with Pakistan $(267,428)$, Spain $(252,123)$, Iran $(232,863)$, and Colombia $(226,373)$. However, no countries 
have the same trend as Bangladesh in terms of days since the fifth confirmed deaths until now. The pandemic has shown us how quickly a new epidemic will catch up and spread. Comprehension is expected with an eruption in clinical and epidemiological information and research. Therefore, the goal of this research is to open up whatever resources we have to help the public health authorities, researchers, and clinicians in Bangladesh in mitigating and handling this crisis. The study presented here, using our designed dataset "Bangladesh COVID-19 Daily Dataset," focused on both exploratory and visual exploratory data analyses. All the analyses with the dataset were performed using Tableau Desktop Professional Edition 2020.1.2 64-bit version (https://www.tableau.com/) support on a windows-based local computer platform, using Open Street Map (https:/www.openstreetmap.org/) and Map Box (https://www.mapbox.com/) for interactive map visualization in the research laboratory of Dhaka International University (DIU), Bangladesh. Lastly, our research team believes it is crucial to produce accurate, realtime, and reliable data for emerging disease outbreaks, which will help generate credible information that can reinforce which inform policy taking in public health sector.

\section{Conclusion}

This report analyzed the data focusing on specific criteria including public awareness, case management, infection control, surveillance, quarantine facility, and trend analysis with other countries. Consequently, this is, to the best of our knowledge, the first initiative of analyzing and visualizing realworld time series COVID-19 data of Bangladesh in such a way that health professionals and researchers around the globe can grasp its severity clearly. The COVID-19 pandemic has ravaged the lives of people around the world and has become a clinical threat to the general population and healthcare workers around the world. However, awareness on this novel virus (SARS-CoV-2) is still minimal in Bangladesh. This study analyzed the one hundred fifty-nine (159) days situation since the first COVID-19 confirmed patients reported in the country. Additionally, this exploration also implemented and used the country's first publicly available daily COVID-19 case dataset. Also illustrated in this study is the day-wise case review and assessment of epidemiological evidence with SAARC, SEAR, and the top 10 countries worldwide (in terms of confirmed and death cases). Our research team believes this is an early data analysis and visualization approach of a situation that is changing rapidly across the country. Therefore, as the more we learn about this SARS-CoV-2 virus and its associated outbreaks, the better we can respond. We will continue to monitor and update the epidemiological data of COVID-19 outbreak in the country in the upcoming days through the developed dataset.
Acknowledgments The reviewers and editors are gratefully acknowledged for their critical review. The authors would like to acknowledge the Directorate General of Health Services (DGHS) for their regular press release. Also, we would like to acknowledge the Institute of Epidemiology, Disease Control and Research (IEDCR) for their timely situational reports on COVID-19. We are also highly grateful to Ministry of Health and Family Welfare (MoHFW) for making the data publicly available in the first place. The authors would also like to acknowledge that this article is also available as a preprint. Preprint version of this article is deposited in medRxiv (https://doi.org/10.1101/2020.06.30. 20143909) deposited on July 2, 2020.

Authors' Contributions All authors conceptualized and designed the study. SKD and MR had the idea and designed the study and had full access to all the data in the study and take the responsibility for the data and accuracy of the data analysis with their visualization. MR, URS, and AH contributed to the writing and critical revision of the article. All the visualization and data presentation methods were developed by SKD and MR. All authors contributed to data acquisition and data analysis, and reviewed and approved the final version.

Data Availability The datasets generated and analyzed during the current study are available in the Kaggle repository [https://www.kaggle.com/ samratkumardey/bangladesh-covid19-daily-dataset].

\section{Compliance with Ethical Standards}

Conflict of Interest The authors declare that they have no conflict of interest.

Ethics Approval and Consent to Participate Not applicable.

Consent for Publication Not applicable.

Abbreviations CDC, Center for Disease Control and Prevention; CFR, case fatality ratio; DGHS, Directorate General of Health Services; IEDCR, Institute of Epidemiology, Disease Control and Research; IHR, International Health Regulation; MHFW, Ministry of Health and Family Welfare; PHEIC, Public Health Emergency of International Concern; rtPCR, reverse transcription polymerase chain reaction; SAARC, South Asian Association for Regional Cooperation; SARS-CoV-2, severe acute respiratory syndrome coronavirus 2; SEAR, South East Asian Region; VEDA, visual exploratory data analysis; WHO, World Health Organization

\section{References}

1. Directorate General of Health Services (DGHS). Health Bulletin 2018, Management Information System. https://dghs.gov.bd/ images/docs/Publicaations/HB\%202018\%20final.pdf (accessed April 12, 2020).

2. Huang C, Wang Y, Li X, et al. Clinical features of patients with 2019 novel coronavirus in Wuhan, China. Lancet. 2020. https://doi. org/10.1016/S0140-6736(20)30183-5.

3. Ksiazek TG, Erdman D, Goldsmith CS, Zaki SR, Peret T, Emery S, et al. A novel coronavirus associated with severe acute respiratory syndrome. N Engl J Med. 2003;348:1953-66.

4. Lu R, Zhao X, Li J, Niu P, Yang B, Wu H, et al. Genomic characterisation and epidemiology of 2019 novel coronavirus: implications for virus origins and receptor binding. Lancet. 2020;395:565-74.

5. Zhu N, Zhang D, Wang W, Li X, Yang B, Song J, et al. A novel coronavirus from patients with pneumonia in China, 2019. N Engl J Med. 2020;382:727-33. https://doi.org/10.1056/NEJMoa2001017. 
6. WHO. Summary of probable SARS cases with onset of illness from 1 November 2002 to 31 July 2003. Dec 31, 2003. https://www.who.int/ csr/sars/country/table2004_04_21/en/ (accessed April 10, 2020).

7. WHO. Middle East respiratory syndrome coronavirus (MERSCoV). November, 2019. http://www.who.int/emergencies/merscov/en/ (accessed April 10, 2020).

8. Kuiken T, Fouchier RAM, Schutten M, Rimmelzwaan GF, van Amerongen G, van Riel D, et al. Newly discovered coronavirus as the primary cause of severe acute respiratory syndrome. Lancet. 2003;362:263-70.

9. Drosten C, Günther S, Preiser W, van der Werf S, Brodt HR, Becker S, et al. Identification of a novel coronavirus in patients with severe acute respiratory syndrome. N Engl J Med. 2003;348:1967-76.

10. de Groot RJ, Baker SC, Baric RS, Brown CS, Drosten C, Enjuanes L, et al. Middle East respiratory syndrome coronavirus (MERSCoV): announcement of the Coronavirus Study Group. J Virol. 2013;87:7790-2.

11. Zaki AM, van Boheemen S, Bestebroer TM, Osterhaus ADME, Fouchier RAM. Isolation of a novel coronavirus from a man with pneumonia in Saudi Arabia. N Engl J Med. 2012;367:1814-20.

12. World Health Organization (WHO). Statement on the second meeting of the International Health Regulations (2005) Emergency Committee regarding the outbreak of novel coronavirus (2019-
nCoV). https://www.who.int/news-room/detail/30-01-2020statement-on-the-second-meeting-of-the-international-healthregulations-(2005)-emergency-committee-regarding-the-outbreakof-novel-coronavirus-(2019-ncov) (accessed April 10, 2020).

13. World Health Organization (WHO). Coronavirus disease 2019 (COVID-19) Situation Report-206 https://www.who.int/docs/ default-source/coronaviruse/situation-reports/20200813-covid-19sitrep-206.pdf?sfvrsn=bf38f66b 6 (accessed August 14, 2020).

14. Dey SK, Rahman MM, Siddiqi UR, Howlader A. Analyzing the epidemiological outbreak of COVID-19: a visual exploratory data analysis approach. J Med Virol. 2020;92:632-8. https://doi.org/10. 1002/jmv.25743.

15. Samrat Kumar Dey, "Bangladesh COVID-19 Daily Dataset." Kaggle, https://doi.org/10.34740/KAGGLE/DSV/1085294.

16. Institute of Epidemiology, Disease Control and Research (IEDCR). August, 2020. COVID-19 situation report (on 15 August 2020). https://corona.gov.bd/storage/press-releases/August2020/ DNChFppaELcHMqgLhGrj.pdf (accessed August 15, 2020).

Publisher's Note Springer Nature remains neutral with regard to jurisdictional claims in published maps and institutional affiliations. 